\section{REPRESENTASI INDHANG DALAM KESENIAN LENGGER}

\section{BANYUMAS}

\section{Wien Pudji Priyanto \\ FBS Univeritas Negeri Yogyakarta}

Abstrak

Kesenian Lengger merupakan salah satu bentuk kesenian khas Banyumas yang dilaksanakan berkaitan dengan upacara mulai menanam padi sampai dengan panen padi usai. Dalam pementasannya kesenian ini terbagi menjadi empat babak yaitu, (1) babak Gambyongan, (2) babak Badutan, (3) babak Ebeg-ebegan (Jathilan) dan, (4) babak Baladewan. Masyarakat meyakin bahwa penari Lengger atau Jathilan yang memiliki Indhang pasti dalam pementasannya memiliki kemampuan, ketrampilan, kekuatan yang lebih ibandingkan dengan mereka yang tidak memiliki indhang. Indhang diperoleh dengan cara menjalankan Laku yaitu bersemadi/konsentrasi di tempat/makam yang dianggap keramat baik oleh kelompok kesenian maupun masyarakat setempat. Penari yang kerasukan Indhang akan memiliki daya tarik dan kekuatan tersendiri misalnya mampu menari berjam-jam tanpa lelah, memilik aura atau pamor yang berbeda dengan aslinya, untuk indhang jathilan dapa aura atau para diluar ke penuat penar kat penari lengger yang kerasukan indhang maka akan dapat mengobati anak atau seseorang yang sedang sakit dengan cara
memberikan air putih yang telah didoakan.

Kata Kunci : Representasi, Indhang dan Kesenian Lengger.

\section{PENDAHULUAN}

Kesenian adalah salah satu bagian dari kebudayaan dan merupakan hasil budi daya manusia. Bentuk kesenian yang ada di Indonesia adalah seni musik, seni lukis, seni drama, seni sastra dan seni tari. Perwujudan seni yang ada di masyarakat merupakan cermin dari kepribadian hidup masyarakat. Driyarkara (1980:8) menyatakan bahwa kesenian selalu melekat pada kehidupan manusia, di mana ada manusia di situ pasti ada kesenian. Selanjutnya Wardhana (1960:6) menyatakan pada hakikatnya kesenian adalah buah budi manusia dalam menyatakan nilai-nilai keindahan dan keluhuran lewat berbagai media cabang seni. Suwandono (1984:40) mengatakan bahwa kesenian, dalam hal ini seni tari adalah milik masyarakat sehingga pengungkapannya merupakan cermin alam pikiran dan tata kehidupan daerah itu sendiri. Tinggi rendahnya peradaban suatu bangsa dapat dilihat dari kebudayaan atau kesenian yang dimilikinya, oleh sebab itu kesenian sebagai salah satu bagian dari kebudayaan perlu dilestarikan dan dikembangkan.

Banyumas sebagai salah satu bagian wilayah propinsi Jawa Tengah, memiliki berbagai macam budaya, adat istiadat, dialek, dan kesenian yang menarik, hal tersebut dikarenakan letak geografis Banyumas yang berada pada perbatasan dua etnis yang berbeda yaitu masyarakat Jawa Barat dengan etnik Sunda. Oleh sebab itu, pengaruh kebudayaan dan kesenian kedua etnis yang berbeda menjadi cukup kuat terhadap masyarakat Banyumas. Kesenian khas banyumas tersebar di hampir seluruh pelosok daerah seperti di Purwokerto, Cilacap, Banjarnegara, Purbalingga, Gombong, Wonosobo, Kebumen, Purworejo, Kulon Progo, dan Magelang. Kesenian di Banyumas pada umumnya merupakan seni pertunjukan rakyat yang memiliki fungsi-fungsi tertentu yang berkaitan dengan kehidupan masyarakat pemiliknya. Kesenian yang berasal dari di daerah Banyumas antaralain, Aplang, Buncis, Sintren, Angguk, Ebeg atau Jathilan, Dhames, Baritan, Ujungan, Gamelan Calung, Wayang kulit, Jemblung, Begalan, Aksi muda, Rodat, Dhaeng, Sintren, Ronggeng, Ketoprak, Dagelan, dan Lengger Calung. Kesenian lengger merupakan salah satu kesenian yang ada dan berkembang di Banyumas sampai saat ini. Kesenian lengger sebagai seni rakyat pada awalnya berkembang di desa-desa atau daerah pertanian dan kesenian ini dapat disebut tarian rakyat pinggiran.

Banyumas terletak jauh dari keraton, baik keraton Yogyakarta Hadiningrat atau Mataram maupun keraton Surakarta atau Pajang serta Pajajaran Jawa Barat, sehingga Banyumas pernah menjadi pusat kekuasaan wilayah yaitu sebuah Kadipaten. Kadipaten Banyumas sejak didirikan oleh R. Jaka Kaiman atau Adipati Mrapat pada kurang lebih tahun 1582 selalu berada dalam bayang-bayang kebesaran keraton Pajang atau Mataram. Oleh karena itu, Banyumas tidak pernah menjadi pusat kebudayaan. Budaya Banyumas oleh banyak orang dianggap sebagai budaya pinggiran, budaya desa atau budaya petani. Logat dialek banyumasan yang medhok dan kasar sering dianggap sebagai cermin dari orang pinggiran/desa yang kurang mengerti unggah-ungguh. Di daerah inilah kesenian lengger hidup dan tumbuh subur.

Kesenian lengger sebagai salah satu bentuk kebudayaan masyarakat Banyumas merupakan seni rakyat yang cukup tua dan merupakan warisan nenek moyang atau leluhur masyarakat Banyumas. Pertunjukan kesenian lengger dilakukan dalam waktu semalam suntuk dengan penari laki-laki. Penari lengger menari sambil menyanyi atau nyinden, diiringi oleh gamelan calung, sehingga sering disebut lengger calung. Fungsi kesenian lengger tersebut pada awalnya merupakan bagian dari ritual (sakral) dalam upacara baritan (upacara syukuran keberhasilan/pasca panen)

Fenomena yang muncul di masyarakat Banyumas bahwa di dalam pertunjukan lengger terdapat kekuatan gaib yang merasuk dalam tubuh penari sehingga penari memiliki kekuatan yang lebih dibandingkan dengan penaripenari lainnya. Kekuatan gaib yang merasuki penari tersebut disebut indhang. Keberadaan indhang sangat terlihat melalui para penari yang sedang menari dan 
menyanyi (nembang) pada babak awal yaitu gambyongan dan pada babak ebegebegan. Kekuatan indhang juga diaktualisasikan dalam syair tembang yang lebih tepat disebut "mantra". Mantra berfungsi untuk mendatangkan atau mengundang indhang.

Penari yang telah kerasukan indhang pada babak lenggeran dan ebeg-ebegan akan mencapai keadaan trance yang membuatnya mampu melakukan hal-hal yang tidak masuk akal, misalnya: menari dan menyanyi dengan kekuatan yang lebih, memakan pecahan kaca tanpa terluka, memegang bara api tanpa terbakar, makan arang, makan bunga/kembang, kemenyan dan lain sebagainya. Pada babak gambyongan penari akan sanggup menari selama berjam-jam tanpa lelah atau tariannya kelihatan indah dan erotis, serta memiliki daya tarik yang luar biasa.

Lengger sebagai kesenian rakyat yang digunakan dalam upacara-upacara kesuburan menjadi alat yang dapat membantu para petani mengungkapkan sukacita di depan sang pencipta yang telah memberi mereka hasil panen yang baik. Gerakan-gerakan tarian lengger yang erotis sekaligus menyimbolkan perkawinan para dewa yang berbuah pada panen yang melimpah. Orang yang tidak memahami kaitan tarian ini dengan latar belakang keyakinan mereka akan dengan mudah memandang dan menilai tarian ini sebagai tarian yang seronok.

Pada tahap selanjutnya manusia menyadari bahwa dunia mereka tidak sepenuhnya dikuasi oleh kekautan gaib. Manusia adalah penguasa dunianya. Keberhasilan panen tidak tergantung kepada bagaimana para dewa, tetapi tergantung pada kegiatan manusia. Mereka masih meyakini bahwa panen merupakan berkah dari yang Maha Kuasa, tetapi berkah itu diterima sebagai buah usaha mereka. Kesenian lengger pun berubah fungsi dari fungsi sakral untuk mengenang dan menghadirkan tindakan para dewa menjadi perangkat sosial masyarakat desa, yaitu untuk bersyukur atas keberhasilan panen. Bahkan, selanjutnya bergeser menjadi tarian profan, yaitu sekedar sebagai hiburan atau tontonan. Di sini terjadi diferensiasi makna terhadap seni lengger. Menurut Van Peursen tahap ini disebut sebagai tahap ontologis. Tahap ontologis adalah tahap pada saat manusia menyadari dirinya sebagai subjek yang berhadapan dengan objek (Peursen. 1976: 18).

Meskipun kesenian lengger sudah bergeser menjadi sarana hiburan, tetapi di dalamnya juga masih terdapat keyakinan atau kepercayaan tertentu. Di dalam kesenian ini masih terdapat unsur-unsur yang masih "primitif" dan mistis. Unsur mistis yang dimaksud adalah keyakinan adanya roh halus yang merasuk dalam diri penari yang disebut indang. Gambaran mengenai keadaan masyarakat pada mitosmitos yang dahulu pernah hidup dan mereka yakini. Kehadiran indhang yang merasuki para penari lengger masih tetap diyakini keberadaannya. Dari latar belakang di atas, penulis akan memaparkan dan mendeskripsikan kesenian lengger dan representasi indhang dalam kesenian lengger di Banyumas.

\section{HAKIKAT KESENIAN LENGGER}

\section{Sejarah Kesenian Lengger}

Istilah lengger sampai saat ini masih dalam perdebatan. Ada yang mengatakan lengger adalah nama lokal Banyumas untuk tarian yang biasanya disebut ronggeng. Koentjaraningrat dalam buku kebudayaan Jawa menulis bahwa dalam budaya Bagelen para penari teledhek disebut ronggeng. Menurut Koentjaraningrat seorang penari ronggeng sudah mulai menari sejak berusia antara delapan sampai sepuluh tahun. Seorang penari anak-anak seperti itu biasanya adalah anak gadis ketua rombongan tersebut dan ia menarikan tarian teledhek serta menyanyikan nyanyian anak-anak (dolanan lare). Rakyat di daerah Bagelen menyebut penari ronggeng yang masih anak-anak itu lengger. Seorang lengger belum tentu menjadi seorang ronggeng bila ia dewasa, akan tetapi sebaliknya seorang ronggeng biasanya berasal dari lengger (Koentjaraningrat, 1994: 221).

Berbeda dengan pendapat Koentjaraningrat, pendapat lain mengatakan bahwa lengger merupakan akronim dari leng dan ngger. Dikiranya para penari itu adalah leng (lubang) artinya wanita, ternyata jengger (terjulur) artinya pria (Kodari, 1991: 60). Namun demikian, istilah ini tetap dipakai sampai sekarang, walaupun para penari kini adalah wanita. Dalam Bausastra (kamus) JawaIndonesia yang disusun oleh S. Prawiroatmojo yang diterbitkan tahun 1957, disebutkan bahwa lengger adalah penari pria. Jadi, sampai dengan tahun 1957 para penari lengger jelas pria.

Kesenian semacam lengger ini sebenarnya tersebar di mana-mana meskipun bentuknya berbeda-beda. Misalnya: Ronggeng Melayu, Gandrung Banyuwangi, Dombret Karawang, Cokek Jakarta, Gambyong Keraton, tayub atau teledhek Wonosari, sintren pesisiran, dan sebagainya (Koentjaraningrat, 1994: 211-228). Perbedaan lengger Banyumas dengan tari-tarian tersebut di atas, selain struktur koreografi, bentuk penyajiannya, juga alat musik iringan dan lagu-lagu yang dinyanyikannya. Untuk kesenian lengger biasanya diiringi oleh gamelan atau karawitan yang disebut calung, serta lagu dan syair tembang dialek khas Banyumasan.

Menurut asal usulnya tarian lengger adalah semacam ungkapan rasa terima kasih kepada dewa-dewi kesuburan. Menurut ahmad tohari pada zaman dahulu di daerah banyumas tarian lengger banyak ditarikan pada masa sesudah panen sebagai ungkapan syukur masyarakat terhadap para dewa yang telah memberikan rejeki pendapat tohari ini sesuai dengan pendapat koentjaraningrat tentang tarian ledhek (koentjaraningrat. 1994: 211-212). Menurut koentjaraningrat masa sesudah panen adalah masa untuk bersukaria bagi para petani. Pada saat itu para penari ledhek sibuk melayani pesanan untuk menari. Jadi, boleh dikatakan bahwa tarian lengger pada awalnya adalah sebuah tarian religius 
atau tarian keagamaan lokal. Menurut ahmad tohari ada kemungkinan lengger sebagai tarian berasal dari india atau merupakan pengaruh agama hindu yang masih tersisa sampai sekarang ini. Tarian tersebut merupakan hasil pengaruh dari kegiatan ritus keagamaan di india selatan, yaitu pesta seks di pusat keagamaan (kuil) sebagai sarana pemujaan terhadap dewi durga. Kegiatan seksual sebagai ritus pemujaan seperti itu pada saat ini masih diyakini dan dijalankan orang di beberapa tempat, misalnya di gunung kemukus, boyolali, jawa tengah untuk memuja pengeran samudra. Ben suharto dalam buku tayub: pertunjukan dan ritus kesuburan menguraikan bahwa tayub (tarian sejenis dengan tari lengger) di masa lampau kiranya mempunyai kaitan dengan kepercayaan asli yang telah berpadu dengan ajaran hinduisme dari sekte tertentu.

Dalam Hinduisme di India pada masa lampau ada golongan (sekte) mistikus, yaitu golongan ciwa cakra tantrayana yang di dalam cita-citanya mengejar moksa mencari jalan sesingkat-singkatnya antara lain dengan persetubuhan (maithuna). Golongan ini menyembah chakti dari ciwa yaitu uma atau durga. Dalam aliran ini yang bagi manusia biasa terlarang bagi aliran ini justru menjadi upacara tersuci. Menurut paham mereka, tidak ada sesuatu pun yang kotor bagi manusia yang bersih. Lima larangan yaitu mamsa (daging), matsya (ikan), madya (alkohol), maithuna (persetubuhan), dan mudra (sikap tangan) bahkan dianggap mampu menimbulkan tenaga-tenaga gaib, bila dilakukan secara berlebihan. Dengan cara ini mereka melakukannya sebagai upacara (Suharto, 1999: 4-8). Prinsip asal mula kehidupan yang lahir lewat persatuan laki-laki dan perempuan juga berlaku bagi dewa, agar mereka dapat melanggengkan kehidupan, maka timbul dari para dewa yang disebut chakti, misalnya cahkti dari wisnu adalah laksmi atau sri yang merupakan dewi kebahagiaan atau dewi kesuburan.

Di dalam tradisi keagamaan, ritual dan penghormatan kepada dewi kesuburan dalam kesenian tradisional di manapun berada biasanya selalu dekat dengan pesta seks. Ketika ajaran Hindu sampai di Jawa ajaran dan tarian itu terbawa, dan mengalami inkulturasi dengan keyakinan akan dewi Sri sebagai dewi padi. Pada zaman dahulu di daerah Banyumas tarian lengger dimainkan pada masa sesudah panen sebagai ungkapan syukur masyarakat terhadap para dewa yang telah memberikan rejeki. Boleh dikatakan bahwa tarian lengger pada awalnya adalah sebuah tarian religius atau tarian keagamaan lokal. Sebagai tarian keagaamaan, lengger belum menjadi seni pertunjukan seperti sekarang ini dan oleh karenanya juga tidak memasang tarif.

Dinas pariwisata dan kebudayaan Banyumas (2001: 23) menyatakan bahwa lengger calung adalah seni pertunjukan khas Banyumas yang dilakukan oleh penari wanita. Kata lengger merupakan penggabungan dari dua kata menjadi bentuk baru, yaitu kata leng dan jengger. Kata Leng berarti lubang identik dengan kelamin perempuan dan jengger merupakan mahkota kepala alat kelamin pada laki-laki, sedangkan jengger merupakan simbol atau tanda kelamin sekunder pada ayam jantan yang melambangkan sifat jantan bagi seorang laki-laki. Hal tersebut didukung oleh pernyataan pigeud dalam bukunya javans volksvertoningen, (ivone, 1986: 34-35) yang menyatakan bahwa di banyumas khususnya, terdapat lengger yaitu pertunjukan dengan penari laki-laki dalam bentuk travesti yang diiringi musik dan beberapa badut. Travesti adalah seorang pria/laki-laki yang berperilaku ke wanita-wanitaan dan senang berdandan atau bersolek serta menari tarian wanita.

\section{Bentuk Penyajian Kesenian Lengger}

Pertunjukan kesenian tradisional lengger calung dibagi menjadi empat babak yaitu (a) babak gambyongan/lenggeran, (b) babak badutan, (c) babak kuda calung (ebeg-ebegan), dan (d) babak baladewan. Pertama, babak Gambyongan, yaitu munculnya tari gambyong yang ditarikan oleh penari wanita, menggambarkan keluwesan remaja perempuan yang sedang beranjak dewasa, mereka melakukan gerak bersolek atau berhias diri agar menjadi cantik sehingga banyak pemuda tertarik. Dalam Kamus Besar Bahasa Indonesia (1995: 288) tari gambyong adalah sebuah tarian yang menggambarkan keluwesan seorang wanita/perempuan. Tarian ini sebagai pembuka dalam kesenian lengger calung, dan mempunyai makna ucapan selamat datang dan menyaksikan pertunjukan. Di samping menari, penari diwajibkan melantunkan tembang-tembang atau gendhing banyumasan sehingga membuat suasana menjadi gembira, dan meriah. Pada babak ini sering dimanfaatkan oleh penonton untuk meminta lagu-lagu atau gendhing Banyumas bahkan dapat untuk ngibing atau menari bersama. Sebelum permintaan lagu dipenuhi maka si pemesan menyisipkan uang sebagai tips atau tambahan kepada penari lenggernya.

Kedua, Babak Badutan, pada babak kedua ini dimaksudkan untuk memberikan waktu istirahat kepada penari lengger selama kurang lebih 30 menit, jumlah penari badutan ini biasanya 2 orang, bisa laki-laki semua atau pasangan laki-laki dan perempuan. Mereka menari dengan gerakan yang lucu sehingga dapat menghibur penonton, kemudian biasanya dilanjutkan dengan melawak dengan dialek banyumasan.

Ketiga, babak ebeg-ebegan atau kuda calung. Babak ketiga ini biasanya dilakukan pada tengah malam di mana penari kuda calung atau ebeg ini melakukan trans atau ndadi (wuru/mendem). Pada babak ini biasanya penonton ingin melihat bagaimana seorang pemain menari dalam keadaan ndadi, kemudian melakukan kegiatan atau atraksi yang aneh-aneh, misalnya makan bunga, makan kaca, makan bara api, minumair bunga, Kelapa muda yang dikupas dengan gigi pemainnya, sintrenan atraksi akrobat dan magic. 
Keempat, babak akhir yaitu Baladewan. Selanjutnya babak terakhir yaitu munculnya penari yang menarikan tari Baladewan, pada adegan ini merupakan penggambaran bahwa semua roh leluhur kesenian lengger kembali ke tempat mereka bersemayam. Konon mereka adalah para dewa yang bertugas untuk membantu manusia dalam kegiatan.

Iringan yang digunakan adalah instrumen/gamelan calung yang terbuat dari bambu laras slendro dan pelog. Gendhing yang dimainkan adalah gendhinggendhing dan tembang khas Banyumas. Estetika yang ada pada gending Banyumasan terdapat pada cengkok dan bentuk fisik instrumen yang unik, pola pukulan instrumen yang bersautan atau imbal menjadi dominan dan khas serta tembang atau nyanyian dengan cengkok, pengucapan khas banyumas.

Calung adalah perangkat alat musik yang terbuat dari bambu wulung mirip dengan angklung dari Jawa barat dan dilaras seperti gamelan jawa yaitu slendro dan pelog. Gamelan calung terdiri dari gambang barung, gambang penerus, dhendhem, kenong, gong, tiup dan kendang. Dalam penyajiannya gamelan calung diiringi penyanyi wanita yang lazim disebut sinden. Aransemen musikal yang disajikan berupa gending-gendhing Banyumasan antara lain Ricikricik, Eling-eling, Gunungsari, Sekar gadung, Unthuluwuk, Renggongmanis, Kulu-kulu, Bendrong Kulon, Godril, Senggot, Warudoyong, Ebeg-ebegan Kembang Glepang, dan Randa Nunut. Calung konon merupakan akronim dari kata carang pring wulung (pucuk bambu wulung) atau dicacah melung-melung (dipukul bersuara nyaring). Perangkat musik ini berlaras slendro dengan nadanada 1 (ji), 2 (ro), 3 (lu), 5 ( $\mathrm{ma}$ ), dan 6 (nem) dan laras pelog yang bernada 1 (ji), 2 (ro), 3 (lu), 4(pat), 5 (ma), 6 (nem) dan 7 (pi) sama dengan laras gamelan Jawa. Jumlah pengrawit adalah enam orang dan vokal dua orang terdiri dari sinden putri serta vokal putra.

Representasi Indhang dalam Kesenian Lengger

Hasil panen masyarakat banyumas yang ada diyakini sebagai berkat perkawinan Dewi Sri dan Djakasudana (geertz, 1960:81). Masa sesudah panen merupakan saat bagi para petani untuk bersyukur dan mengadakan pesta. Pada saat seperti itulah dimainkan tari lengger (koentjaraningrat, 1994:211). Pada masyarakat yang percaya adanya mitos-mitos seperti itu menimbulkan adanya mitos terhadap penari lengger yang dapat menarik perhatian penonton selama pertunjukan. Pada kesenian lengger dikenal adanya nyanyian, doa, dan tarian sebagai tradisi ritual untuk menghadirkan kekuatan tokoh-tokoh mistis tersebut. Fungsi tarian tersebut adalah menciptakan atau mengundang kekuatan yang memiliki daya tumbuh bagi tumbuh-tumbuhan atau datangnya hujan. Dalam pengungkapannya sering dijumpai unsur-unsur seksual yang terkandung di dalamnya. Seperti, saling mendekatkan dan menggoyang-goyangkan pantat.
Secara umum dapat diketahui bahwa sebagian besar upacara kesuburan tumbuhtumbuhan selalu dimulai dengan kesuburan manusia sendiri. Hal ini mengingat bahwa bagi dunia kehidupan yang sangat sederhana dan primitif, mereka masih sangat menyatu dengan lingkungan alam serta sadar keharusan keterlibatannya dalam menjaga keseimbangannya.

Lengger sebagai tarian rakyat yang digunakan dalam upacara-upacara kesuburan juga tidak terhindarkan dari unsur-unsur erotisme. Orang yang tidak memahami kaitan tarian ini dengan latar belakang keyakinan mereka akan dengan mudah memandang tarian ini sebagai tarian yang tidak senonoh. Padahal sebagai tarian rakyat lengger menjadi perangkat yang dapat membantu para petani mengungkapkan sukacita di depan sang pencipta yang telah memberi mereka hasil panen yang baik. Gerakan-gerakan tarian lengger yang erotis sekaligus menyimbolkan perkawinaan para dewa yang berbuah pada panen yang melimpah.

Keyakinan masyarakat terhadap adanya indhang sebagai roh yang membantu hidupnya kesenian tradisional tidak dapat dilepaskan dari adanya mitos-mitos keberadaan roh halus dalam masyarakat. Mereka percaya bahwa roh para Leluhur atau nenek moyang masih ada dan hidup di alam lain di dunia manusia. Masyarakat menghadapi pertanyaan-pertanyaan berkaitan dengan fenomena-fenomena yang mereka temukan dalam kehidupan. Lewat mitosmitos tersebut, masyarakat menemukan jawaban atas pertanyaan-pertanyaan yang tidak terjawab dalam kehidupan mereka. Mitos mencoba menjelaskan cara beradanya sesuatu atau mengapa sesuatu terjadi demikian.

Menurut Eliade mitos menjadi dasar kehidupan sosial dan kebudayaan bagi suatu masyarakat tertentu. Mitos mengungkapkan cara beradanya di dunia atau terjadinya sesuatu. Mitos merupakan realitas kultural yang kompleks dan karena itu sulit untuk memberikan batasan-batasan yang definitif terhadapnya. Eliade memandang mitos sebagai usaha manusia untuk melukiskan lintasan yang supranatural ke dalam dunia. Mitos menjadi suatu kebenaran yang pasti dan menetapkan suatu kebenaran absolut yang tak dapat diganggu gugat. "sesuatu itu demikian karena memang demikian, titik dan habis perkara". Mitos berbicara hanya tentang apa yang disebutnya dengan kenyataan, tentang apa yang pada kenyataannya terjadi. Kenyataan ini merupakan kenyataan kudus karena hanya yang kuduslah yang sungguh-sungguh merupakan kenyataan sejati dan benar. Karena itulah, menurut eliade mitos sama sekali berbeda dengan dongeng. Dongeng bukanlah merupakan kenyataan. Mitos menguakkan suatu tabir misteri, mewahyukan suatu peristiwa primordial yang masih selalu diceritakan dan diulang kembali pada waktu sekarang. Mitos memberikan contoh-contoh model untuk dijadikan referensi tindakan manusia sekarang.

Mitos menjadi dasar tindakan manusia religius, apa yang mereka lakukan adalah apa yang dilakukan oleh para dewa atau leluhur mereka. Mereka 
menemukan contoh-contoh model itu dalam mitos dan setiap tindakan manusia dibenarkan dengan mengambil referensi pada mitos. Menjadi manusia religius berarti hidup dan tinggal dalam lingkungan yang sakral. Semakin religius manusia itu semakin ia mempunyai pegangan contoh model untuk membimbing sikap dan tindakannya.

Persyaratan untuk memperoleh Indhang, (1) telah mengikuti dan melaksanakan proses magang menjadi penari Lengger yang disebut Unthul, (2) Melaksanakan proses Laku atau menjalankan tata aturan yang berlaku, misalnya berpuasa, bersemadi, mandi air bunga setaman dan sebagainya, (3) Taat dengan segala macam pantangan yang digariskan, (4) Memasang sesaji pada hari tertentu, (5) selalu berlatih tembang dan menari sehingga memiliki ketrampilan yang tinggi dan (6) Tidak booleh sombong dan takabur.

Agar setiap pementasan penari selalu dirasuki indhang ada ritus yang harus dilaksanakan oleh penari lengger. Masuknya indhang dalam tubuh penari melalui syair tembang yang lebih tepat disebut "mantra". Mantra berfungsi untuk mendatangkan atau mengundang indhang. Kekuatan mantra lewat syair tembang tersebut dirasakan oleh para penari lengger. Dalam beberapa waktu kemudian penari merasakan ada suatu kekuatan yang memasuki dirinya, penari dalam waktu sesaat merasakan kekuatan yang begitu hebat dan kekuatan itu mengajaknya untuk menyanyi dan menari dengan kekuatan yang lebih dari yang dimilikinya baik itu wajahnya yang begitu terlihat cantik, tenaga yang begitu kuat, menari dan menyanyi selama berjam-jam, bahkan dapat diminta menyembuhkan seseorang yang sedang sakit dengan cara mencium keningnya.

Berbeda dengan indhang yang merasuk kepada penari lengger, pada babak ebeg-ebegan indhang yang datang bukanlah indhang yang baik, tetapi indhang jahat/brangasan sehingga penari ebeg/jathilan yang telah kerasukan indhang akan mencapai keadaan trance yang membuatnya mampu melakukan hal-hal yang tidak masuk akal, misalnya: memakan pecahan kaca tanpa terluka, memegang bara api tanpa menjadi terbakar, duduk dengan menggunakan pisau tetapi tidak terluka, dan ada yang mengajak berkelahi penonton apabila indhang yang masuk merupakan indhang yang jahat dan memiliki dendam dengan seseorang sewaktu hidupnya. Gerak para penari yang sudah kerasukan indhang sangat berbeda dengan gerak penari lainnya. Para penari yang Trance atau Mendem (Ndadi) mereka sudah memiliki kekuatan, stamina yang lebih bahkan mampu melakukan kegiatan di luar jangkauan manusia biasa. Mereka makan kaca/beling, bara api, padi, bunga, kreweng atau pecahan genting dan makan ayam hidup-hidup.

Seperti telah dikemukakan pada bab pendahuluan bahwa fungsi kesenian lengger pada awalnya merupakan bagian dari ritual (sakral) dalam upacara baritan (upacara syukuran keberhasilan/pasca panen). Lengger sebagai kesenian rakyat yang digunakan dalam upacara-upacara kesuburan menjadi alat yang dapat membantu para petani mengungkapkan sukacita di depan sang pencipta (dewa) yang telah memberi mereka hasil panen yang baik.

Pada tahap selanjutnya manusia menyadari bahwa dunia mereka tidak sepenuhnya dikuasi oleh kekautan gaib, manusia adalah penguasa dunianya. Keberhasilan panen tidak tergantung kepada bagaimana kegiatan para dewa, tetapi tergantung pada kegiatan manusia. Mereka masih meyakini bahwa panen merupakan berkah dari yang maha kuasa, tetapi berkah itu diterima sebagai buah usaha mereka. Kesenian lengger pun berubah fungsi dari fungsi sakral untuk mengenangkan dan menghadirkan tindakan para dewa menjadi perangkat sosial masyarakat desa, yaitu untuk bersyukur atas keberhasilan panen. Bahkan, selanjutnya bergeser menjadi tarian profan, yaitu sekedar sebagai hiburan atau tontonan.

\section{SIMPULAN}

Berdasar pada uraian tersebut di atas dapat disimpulkan sebagai berikut. Pertama, kesenian Lengger merupakan salah satu jenis kesenian yang bersifat Religius/Ritual pada tempo dulu, perkembangan sekarang telah berubah menjadi seni hiburan atau pergaulan dan tontonan. Kedua, kesenian Lengger dalam pertunjukannya terdiri dari empat babak yaitu, babak Gambyongan, babak Badutan, babak ebeg-ebegan (Jathilan) dan diakhiri dengan babak Baladewan. Ketiga, kesenian Lengger tempo dulu masih sarat dengan upacara religi dan sakral yaitu masih meyakini adanya Indhang yaitu Roh halus yang merasuk ke tubuh penari, sehingga penampilannya akan menjadi lebih menarik, dan kekuatan yang lebih. Keempat, untuk memperoleh indhang seorang pawang dan penari harus melaksanakan laku yaitu bersemadi atu berdoa di tempat/makam keramat, berpuasa, melaksanakan persyaratan dan pantangan yang berlaku. Kelima, bagi penari yang kerasukan inhang disamping dapat memiliki kemampuan dan ketrampilan yang lebih, juga dipercaya oleh sebagian masyarakat dapat memngobati seseorang yang sedang sakit dengan cara mencium atu mengusap muka pasien dengan tanganya.

\section{DAFTAR PUSTAKA}

Cassirer, Ernst. 1987. Manusia dan Kebudayaan: sebuah Esei Tentang Manusia. Jakarta: PT. Gramedia.

Depdikbud. 1995. Kamus Besar Bahasa Indonesia. Jakarta: Balai Pustaka.

Eliade, Mercea. 1964. Myth and Reality. London: George Allen \& Anwin ltd. Geertz, clifford. 1960. "Religion as Culture System". dalam Interpretation of Cultural. London: The Free Press of Glencoe. 
Koentjaraningrat, 1994. Kebudayaan Jawa. Jakarta: Balai Pustaka.

Kodari, M. 1991. Banyumas Wisata dan Budaya. Purwokerto: Metro Jaya.

Lasor, WS., et.al. 1987. Old Testamen Survey. Michigan: Erdmans Publishing Company.

Lembaga penelitian, 2004. Pedoman Penelitian. Yogyakarta: Lemlit UNY.

Mangunwijaya, YB. 1989. "Memahami Gerakan Rakyat". Dalam Prisma 7

November 1989.

Prawiroadmojo S. 1957. Bausastra (Kamus) Djawa-Indonesia. Surabaya: Express.

Sach, Curt. 1963. World History of the Dance. Terjemahan Bassie Schonberga. New York: WW Norton \& Company.

Soekmono, 1973. Sejarah Kebudayaan Indonesia. Yogyakarta: Kanisius.

Tohari, Ahmad. 1982. Ronggeng dukuh paruk. Jakarta: Gramedia.

Suharto, Ben. 1999. Tayub: Pertunjukan dan Ritus Kesuburan. Jakarta: Masyarakat Seni Pertunjukan Indonesia.

Susanto, Hary. 1987. Mitos Menurut Pemikiran Eliade. Yogyakarta: Kanisius. Triyoga, Ivonne. 1986. Gambyong Banyumasan sebuah Studi Koreologis. Institut seni Indonesia Yogyakarta. 